\title{
FORMACIÓN DE GRÁNULOS ANAEROBIOS SIN LODOS INOCULADOS EN UN REACTOR DE BIOPELÍCULA ANAEROBIA TIPO INTERCAMBIADOR DE CALOR (RBAIC)
}

\section{Ramiro Escalera Vásquez}

\section{RESUMEN}

Se ha estudiado experimentalmente el fenómeno de la formación de gránulos anaerobios en la puesta en marcha de un Reactor de Biopelícula Anaerobia Tipo Intercambiador de Calor (RBAIC), utilizado en el tratamiento de aguas residuales provenientes de una planta de procesamiento de melazas de baja concentración, $0,45 \mathrm{~g}-\mathrm{C} \mathrm{L}^{-1}$. El reactor fue operado en modo de flujo ascendente de un solo paso a bajas temperaturas promedio del líquido $\left(15^{\circ} \mathrm{C} \mathrm{a} 25^{\circ} \mathrm{C}\right)$ y tiempos de retención hidráulica (TRH) de $16 \mathrm{~h}$ y 6,1 h. La granulación puede proceder sin la inoculación de grandes cantidades iniciales de lodo biológico anaerobio. La granulación es posible aún con concentraciones iniciales muy pequeñas de microorganismos, siempre y cuando los mismos estén bien aclimatados al tipo de agua residual y las condiciones ambientales. Es posible tratar tasas de carga orgánica volumétrica entre 1,8 y 3,3 g-DQO $\mathrm{L}^{-1} \mathrm{~d}^{-1}$ a temperaturas promedio menores a $25^{\circ} \mathrm{C}$ con concentraciones de biomasa tan pequeñas como $2 \mathrm{~g}^{-\mathrm{SSV} \mathrm{L}^{-1}}$. En un RBAIC, se pueden formar gránulos de $0,5-2 \mathrm{~mm}$ de diámetro en tres meses a temperaturas promedio menores a $25^{\circ} \mathrm{C}$.

Palabras Clave: Reactor de Biopelícula Anaerobia, Granulación, Tratamiento de Aguas Residuales de Melazas. 